\title{
Radical Scavenging and Catalytic Activity of Fe-Cu Bimetallic Nanoparticles Synthesized from Ixora finlaysoniana Extract
}

\author{
Umer Younas ${ }^{1, *}$, Syed Taimoor Hassan ${ }^{1}$, Faisal Ali ${ }^{1}$, Faiza Hassan ${ }^{1}$, Zohaib Saeed ${ }^{2}$, Muhammad Pervaiz ${ }^{1}$, \\ Safia Khan ${ }^{3, *}$, Fakiha Tul Jannat ${ }^{4}$, Sidra Bibi ${ }^{3}$, Ayesha Sadiqa ${ }^{1}$, Zahid Ali ${ }^{1,5}$, Shahid Iqbal ${ }^{6, *}$, \\ Ayman A. Ghfar ${ }^{7}\left(\right.$, Mohamed Ouladsmane ${ }^{7}$, Murefah Mana AL-Anazy ${ }^{8}$ and Shafaqat Ali $9,10, *$ (D)
}

check for updates

Citation: Younas, U.; Hassan, S.T.; Ali, F.; Hassan, F.; Saeed, Z.; Pervaiz, M.; Khan, S.; Jannat, F.T.; Bibi, S.; Sadiqa, A.; et al. Radical Scavenging and Catalytic Activity of Fe-Cu Bimetallic Nanoparticles Synthesized from Ixora finlaysoniana Extract. Coatings 2021, 11, 813. https:// doi.org/10.3390/coatings11070813

Academic Editor: Natalia V. Kamanina

Received: 29 May 2021

Accepted: 15 June 2021

Published: 5 July 2021

Publisher's Note: MDPI stays neutral with regard to jurisdictional claims in published maps and institutional affiliations.

Copyright: (c) 2021 by the authors. Licensee MDPI, Basel, Switzerland. This article is an open access article distributed under the terms and conditions of the Creative Commons Attribution (CC BY) license (https:// creativecommons.org/licenses/by/ $4.0 /)$.
1 Department of Chemistry, The University of Lahore, Lahore 54590, Pakistan; syedtaimoor91@gmail.com (S.T.H.); faisal.alimsc@gmail.com (F.A.); faiza.hassan@chem.uol.edu.pk (F.H.); mpbhatti786@gmail.com (M.P.); a.sadiqa046@gmail.com (A.S.); zahidchemist521@gmail.com (Z.A.)

2 Department of Chemistry, Government College University, Lahore 54000, Pakistan; zohaibsaeed46@gmail.com

3 Department of Chemistry, Quaid-I-Azam University Islamabad, Islamabad 45320, Pakistan; sidrabibi@chem.qau.edu.pk

4 Department of Chemistry, Government College University, Faisalabad 38000, Pakistan; jannat98@yahoo.com

5 Laboratory of Functional Material, College of Material Science and Engineering, Beijing University of Chemical and Technology, Beijing 100029, China

6 Department of Chemistry, University of Education Jauharabad Campus, Jauharabad 41200, Pakistan

7 Advanced Materials Research Chair, Chemistry Department, College of Science, King Saud University, Riyadh 11451, Saudi Arabia; aghafr@ksu.edu.sa (A.A.G.); mouladsmane@ksu.edu.sa (M.O.)

8 Department of Chemistry, College of Science, Princess Nourah Bint Abdulrahman University, Riyadh 11671, Saudi Arabia; mmalanazy@pnu.edu.sa

9 Department of Environmental Science and Engineering, Government College University, Faisalabad 38000, Pakistan

10 Department of Biological Sciences and Technology, China Medical University, Taichung 40402, Taiwan

* Correspondence: umer.younas@chem.uol.edu.pk (U.Y.); safiakhan@chem.qau.edu.pk (S.K.); ranashahid313@gmail.com (S.I.); shafaqataligill@yahoo.com (S.A.)

Abstract: Iron-copper bimetallic nanoparticles (Fe-Cu BNPs) were prepared via a green synthesis route. Ixora finlaysoniana has been used in this study as a capping and stabilizing agent in the modification of Fe-Cu BNPs. As-synthesized BNPs were characterized using different techniques including UV/Vis spectrophotometry, FTIR, XRD and SEM. A particle size analyzer and SEM studies indicated the particle size to be in the range of 50-200 $\mathrm{nm}$. In addition, degradation of MB dye in an aqueous system and radical-scavenging potential in a DPPH assay were also examined using BNPs. Methylene blue dye degradation in $17 \mathrm{~min}$ was monitored with UV/Vis spectrophotometry, which exhibited the efficiency of Fe-Cu BNPs. Bimetallic nanoparticles were also found to be efficient in neutralizing DPPH free radicals. Furthermore, kinetic studies of both dye degradation and radical scavenging potential are reported in this article. Subsequently, Fe-Cu BNPs synthesized via a green and sustainable method can be employed for dye degradation and free radical-scavenging activities.

Keywords: bimetallic nanoparticles; kinetics; antioxidant studies; catalytic activity

\section{Introduction}

Water pollution has always been a great concern over the years due to a decrease in water levels and an increase in pollution over time [1,2]. Among the many pollutants, dyes are one of the major contributors to water pollution $[3,4]$. Both cationic and anionic dyes as pollutants are a real threat to human life. Textile dyes can cause different diseases, such as cancer [5], cardiac problems [6] and lethal paraphernalia on cells [7]. These dyes stop sunlight reaching marine life, which results in a decrease in photosynthesis processes under water [8]. Therefore, the removal of such hazardous contaminants from water is of major 
interest [9]. For this purpose, a multitude of techniques have been employed for dye degradation, among which nanoparticles of various kinds have gained a lot of attention [10,11]. Many methods have been reported for the modification of nanoparticles, such as thermal and photochemical decomposition, chemical reduction, electrochemical reduction, the sol-gel method, sputtering, the micro-emulsion method, the hydrothermal method, the chemical precipitation method, the green method and the biological method, are frequently used routes for their synthesis [12,13]. Initially, the synthesis of monometallic nanoparticles was focused on by scientists and researchers. Recently, bimetallic nanocomposites have attracted attention due to their synergistic effects in many applications, especially dye degradation [14,15]. Osama Eljamal and coworkers reported the synthesis and characterization of iron-copper bimetallic nanoparticles (Fe-Cu BNPs) for an increase in the yield of methane and to enhance biogas production [16]. Recently, Jianlong Wang and Juntao Tang (2020) introduced novel Fe-Cu BNPs by the solvo-thermal method and used these BNPs in the reduction of sulfamethoxazole (a pharmaceutical pollutant) [17]. In addition, $\mathrm{Fe}-\mathrm{Cu}$ BNPs have been used for the removal of chromium from waste water [18].

Moreover, copper and iron nanoparticles are both commercially important as their annual production amounts to millions of tons and, due to their uses in various industries, their production is likely to increase every year $[19,20]$. Unfortunately, other methods produce various pollutants as precursors that are highly damaging to the environment [21,22]. Therefore, it is necessary to find alternative ways under the umbrella of green chemistry to meet the demand for these nanoparticles in a better and safer way [18]. In green chemistry, there are various ways by which their production can be achieved, including biological waste [22] and plant extracts [23]. Looking at the vast and easy availability of plants, the plant-mediated method was considered for the production of these Fe-Cu BNPs [23].

Herein, Ixora finlaysoniana, also known as jungle flame, was used as a plant source in order to achieve our aim of synthesizing Fe-Cu BNPs in a natural and sustainable way. It is a shrub of the Rubiaceae family normally found in South East Asia, China, India and the Philippines [24].

This family is quite abundant, comprising more than 13,000 species found globally. Due to its medicinal impact, it has been used medically in various parts of the world. Variations in conditions and concentrations were made in order to optimize the most suitable method. This method is both economical and environmentally friendly with the most suitable condition [25]. 2,2-diphenyl-2-picrylhydrazyl hydrate (DPPH) is a nitrogen-centered radical with a maximum absorbance at $517 \mathrm{~nm}$, which is converted to 1,1, diphenyl-2-picryl hydrazine when reacting with electron-accepting species. This hydrogen donation ability leads to the formation of a stable complex of free radicals, resulting in termination of free radical-based reactions [26]. The objectives of the present study were to synthesize $\mathrm{Fe}-\mathrm{Cu}$ BNPs using a green method followed by characterization using UV/Vis spectrophotometry, XRD, FTIR and SEM. In addition, antioxidant and catalytic activities of the synthesized Fe-Cu BNPs were determined.

\section{Materials and Methods}

\subsection{Chemicals and Reagents}

Methylene blue (99.9\%) was purchased from Fisher Scientific, Altrincham, UK and sodium borohydride (99\%), DPPH (99.5\%), $\mathrm{FeSO}_{4}(99 \%)$ and $\mathrm{CuSO}_{4}(99 \%)$ were acquired from Sigma-Aldrich, Taufkirchen, Germany and methanol (98\%) was used as a solvent and was purchased from Unichem, Wuxi, China. All the chemicals and metal precursors were used as received without any further heating or purification treatment.

\subsection{Preparation of Plant Extract}

Ixora plants were collected from WAPDA Town, Model Town and Kalma Chowk nurseries of Lahore, Pakistan. After washing, plants were dried in the shade. In order to attain a constant weight, plants were placed in hot air oven for $3 \mathrm{~h}$ at $60^{\circ} \mathrm{C}$, followed by cutting and grinding. The powdered plant samples were then mixed with methanol 
and the extraction of bioactives was achieved using an orbital shaker for $3 \mathrm{~h}$ at $150 \mathrm{rpm}$. The filtrate obtained was dried using a rotary evaporator and stored at $-4{ }^{\circ} \mathrm{C}$ prior to further use.

\subsection{Nanoparticle Synthesis}

Salt solution was prepared by mixing $\mathrm{FeSO}_{4}$ and $\mathrm{CuSO}_{4}$ in $25 \mathrm{~mL}$ of solvent. The solvent used was a mixture of methanol and water in a 1:3 molar ratio. Similarly, extract solution was prepared by mixing the extract in methanol. Both solutions were mixed at different concentrations to make various ppm solutions, ranging from 50 to $250 \mathrm{ppm}$. The purpose of making solutions at various concentrations was to find out the best concentration which gives satisfactory results. The best concentration was found to be $200 \mathrm{ppm}$ after obtaining its UV/Vis spectra. The selected concentration was then centrifuged and filtered. The filtered sample containing Fe-Cu BNPs was dried at $65^{\circ} \mathrm{C}$ in a vacuum oven for $2 \mathrm{~h}$ before further application. Figure 1 shows the Schematic diagram of Fe-Cu BNPs.

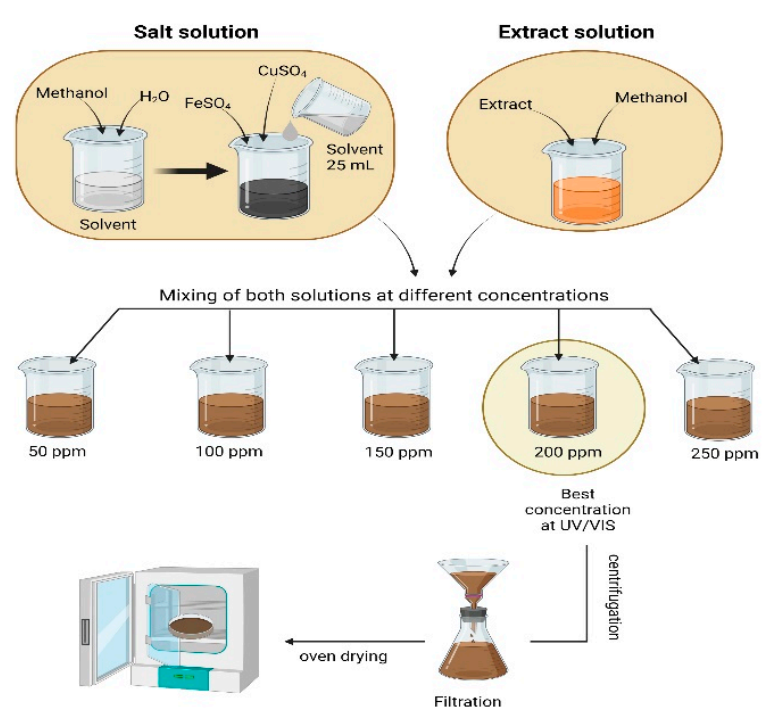

Figure 1. Schematic diagram of Fe-Cu BNPs.

\subsection{Characterization of Nanoparticles}

Synthesis of Fe-Cu BNPs was immediately confirmed using a UV/Vis spectrophotometer and lambda max was recorded on a CECIL-7400ce UV/Vis spectrophotometer (Cecil Instruments Ltd., Cambridge, UK). Particle size analyzer Lite-sizer 500 software version 1.8.1, Anton Paar, Graz, Austria) with a measurement time of $10 \mathrm{~s}$ at $30^{\circ} \mathrm{C}$ with a maximum no of runs (60) was used. FTIR spectra of the Fe-Cu BNPs and aqueous plant extracts were recorded on an FTIR spectrophotometer (IR Prestige 21, Shimadzu, Kyoto, Japan). Additionally, the $\mathrm{X}$-ray diffraction (XRD) studies were carried out at a scanning rate of $0.05 \mathrm{~min}^{-1}$ using a Bruker D8 Advanced (Bruker, Billerica, MA, USA), equipped with a scintillation counter using $\mathrm{Cu} K \alpha$ radiation $(\mathrm{k}=1.5405 \AA$, nickel filter) at an acceleration voltage of 30 KV NOVA SEM 450 (FEI, Hillsboro, OR, USA) was utilized to obtain SEM images of synthesized BNPs and micrographs were obtained at 3 different magnifications.

\subsection{DPPH Radical-Scavenging Potential}

The antioxidant capacity of the BNPs was studied through the evaluation of the free radical-scavenging effect on the 1,1-diphenyl-2-picrylhydrazyl (DPPH) radical. The determination was carried out by following an already reported method [27]. Ten milliliters of BNPs (200, 400 and $600 \mathrm{ppm}$ ) was added to three separate flasks and $90 \mathrm{~mL}$ of distilled water was added followed by the addition of $3.9 \mathrm{~mL}, 25 \mathrm{mM}$ DPPH methanol solution. The mixture was thoroughly vortexed and kept in the dark for $30 \mathrm{~min}$. The absorbance was measured later, at $515 \mathrm{~nm}$, against a blank of methanol without DPPH. Results were 
expressed as the percentage of inhibition of the DPPH radical. The percentage of inhibition of the DPPH radical was calculated according to Equation (1).

$$
\text { DPPH scavenging effect } \%=[(\mathrm{AD}-\mathrm{AS}) / \mathrm{AD}] \times 100
$$

where AD control is the absorbance of DPPH solution without extracts and AS is the absorbance value for the sample.

\subsection{Catalytic Activity}

The catalytic activity for Fe-Cu BNPs was observed following an already published method [28]. Methylene blue $0.086 \mathrm{mM}, \mathrm{NaBH}_{4} 26 \mathrm{mM}$ and Fe-Cu BNPs with a $100 \mathrm{ppm}$ concentration were prepared. In a cuvette of the UV/Vis spectrophotometer, $3 \mathrm{~mL}$ methylene blue, which acted as substrate, and $0.4 \mathrm{~mL}$ of $26 \mathrm{mM}$ sodium borohydride acting as a reducing agent were mixed. In this solution containing the substrate and reducing agent, $0.5 \mathrm{~mL} \mathrm{Fe-Cu} \mathrm{BNP}$ solution was added, which behaved as a catalyst, and all the observations were recorded at $665 \mathrm{~nm}$, the maximum absorbance $\left(\lambda_{\max }\right)$ for methylene blue.

\section{Result and Discussion}

\subsection{UV/Visible Analysis}

$\mathrm{UV} /$ visible spectrophotometric analysis can be an instant preliminary test for the confirmation of nanoparticle formation, as metallic nanoparticles show absorbance in the $\mathrm{UV} /$ Vis region. According to the literature, the absorbance range for iron nanoparticles is 280-350 nm [29], while copper nanoparticles show absorbance from 550-600 nm [30]. During the formation of Fe-Cu BNPs, the shift in absorbance values for iron is $292 \mathrm{~nm}$ and for copper it is $594 \mathrm{~nm}$ as compared to their monometallic counterparts that show absorbance at 325 and $589 \mathrm{~nm}$, respectively, as shown in Figure 2a [31].
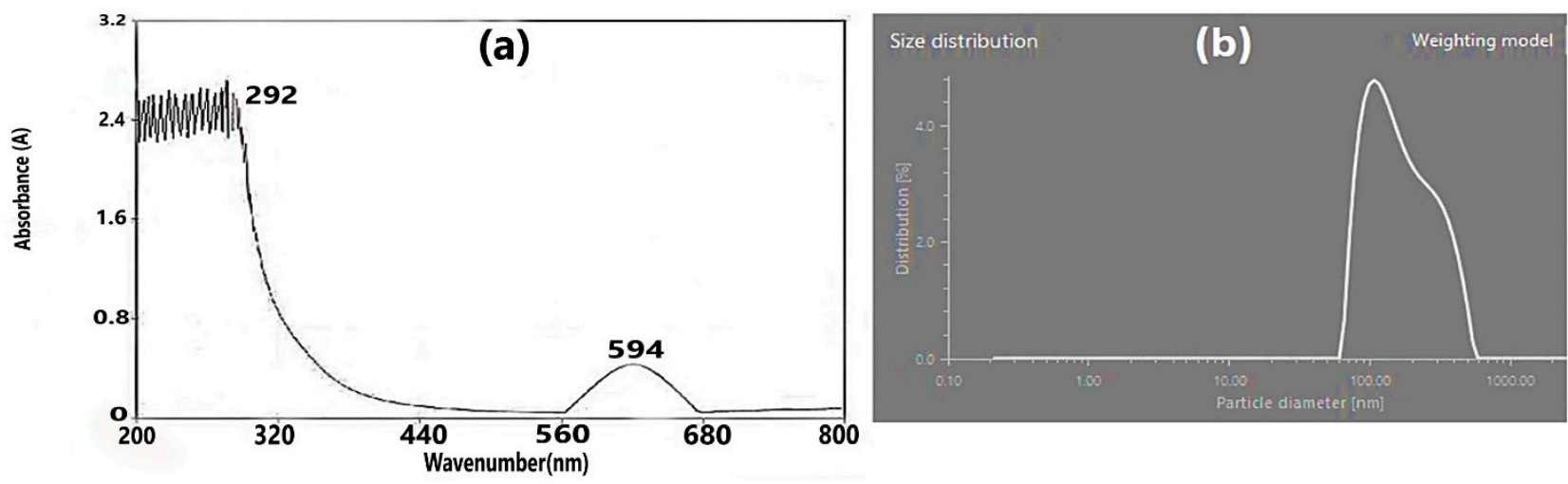

Figure 2. Absorbance peak of Fe-Cu BNPs (a) and particle size distribution of sample (b).

\subsection{Particle Size Analysis}

This technique is employed to find out about the size and distribution range of nanoparticles. It also confirms the presence of nanoparticles by describing the range of the particles. The sample used was in the form of solution and Figure $2 b$ shows the particle size distribution that was obtained. It contains two parameters, particle diameter (horizontally) and distribution frequency (vertically). It clearly shows that nanoparticle ranges below and above $100 \mathrm{~nm}$ were present in the sample [32,33].

\subsection{FTIR Analysis}

The data obtained after FTIR analysis, as shown in Figure 3a, were then compared with an IR chart for the identification and confirmation of relevant components in the provided sample. The dip around $3169 \mathrm{~cm}^{-1}$ is due to $\mathrm{C}-\mathrm{H}$ and hydroxyl and carboxylic group stretching in phenolic acid, gallic acid and protocatechuic acid present in the plant extract. The extract could possibly contain some other secondary metabolites or interfering 
compounds but successful extraction depends upon careful handling and preparation of plant samples. It would also minimize the incorporation of interfering components. FTIR did not indicate the presence of undesired species in the nanoparticles' final form. The dip around $1644 \mathrm{~cm}^{-1}$ is due to $\mathrm{C}=\mathrm{C}$ stretching which is a basic component of most organic biomolecules [23]. All this evidence for the presence of phenolic compound peaks confirms the potential of the extract to reduce $\mathrm{Fe} / \mathrm{Cu}$, which is a strong indicator for the synthesis of target BNPs [26]. In addition, carboxylic acid present at the boundaries of Fe-NPs shows peaks at almost 800 to $850 \mathrm{~cm}^{-1}$, whereas the peak at 1050 to $1111 \mathrm{~cm}^{-1}$ may represent $\mathrm{C}-\mathrm{O}-\mathrm{C}$ attached to $\mathrm{Cu}$ present in BNPs [34].
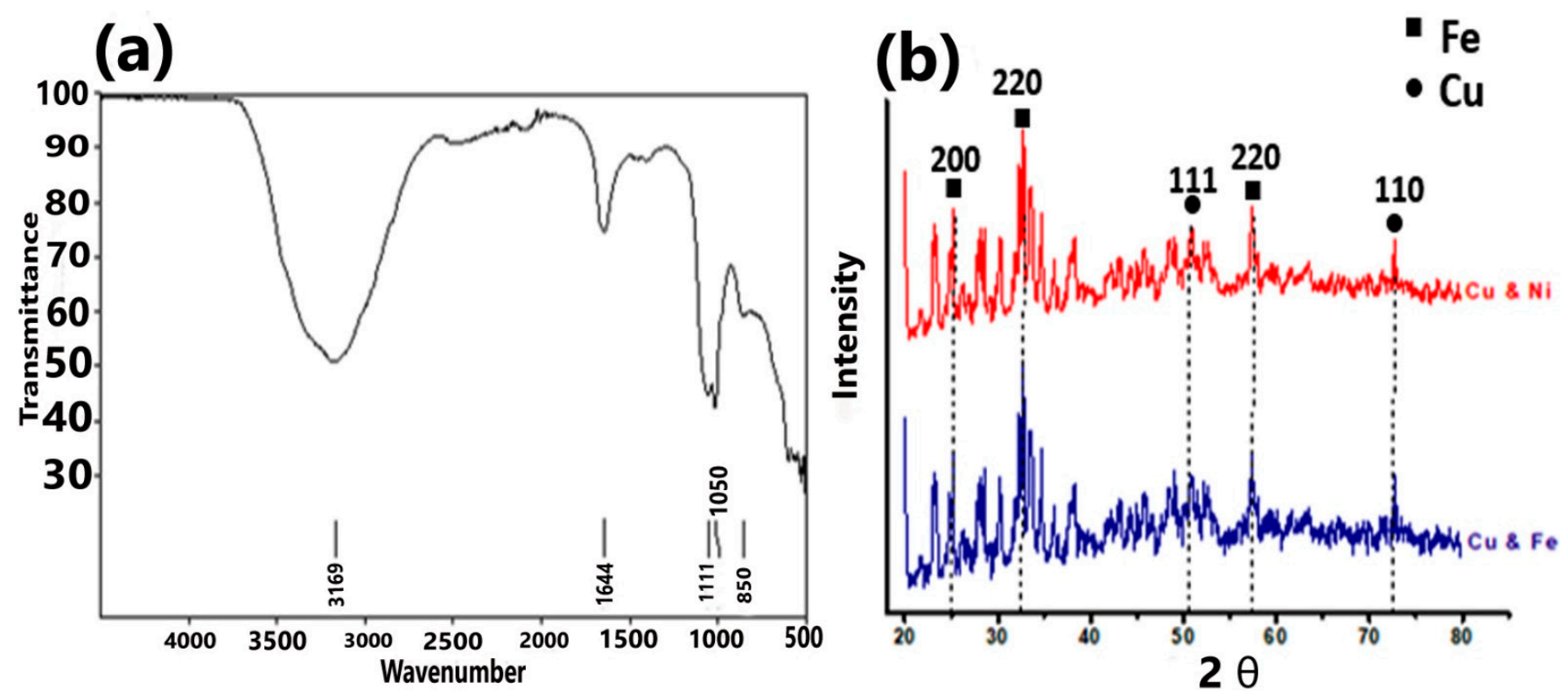

Figure 3. FTIR spectrum (a) and XRD patterns (b) of Fe-Cu BNPs.

\subsection{XRD Analysis}

$\mathrm{X}$-ray diffraction is a very effective technique in determining the morphology and structure of nanoparticles. The peak in Figure $3 \mathrm{~b}$ at $30.0^{\circ}$ relates to $\gamma-\mathrm{Fe}_{2} \mathrm{O}_{3}$ and $57.39^{\circ}$ relates to $\alpha-\mathrm{Fe}_{2} \mathrm{O}_{3}$ (JCPDS 39-1346) while $50.24^{\circ}$ and $74.21^{\circ}$ correspond to $\mathrm{Cu}$ nanoparticles (JCPDS No: 04.0836) [35,36]. The presence of some minor peaks indicates impurity in the form of biomoieties. The sharp and intense peaks confirmed the presence of $\mathrm{Fe} / \mathrm{Cu}$ nanoparticles and their crystalline nature [35]. Sharp peaks indicated the crystalline nature of nanoparticles. In conclusion, for as-synthesized $\mathrm{Fe}-\mathrm{Cu}$ bimetallic nanoparticles, the existence of both the $\mathrm{Fe}$ and $\mathrm{Cu}$ peaks was recognized by a diffractogram.

\subsection{Scanning Electron Microscopy (SEM)}

SEM images of Fe-Cu BNPs were obtained through a NOVA Nano SEM 450. The sample in powder form was used for taking SEM images. The micrographs in Figure $4 a-c$ were obtained at different magnifications (30,50 and $100 \mathrm{~nm}$, respectively). They provide the data regarding morphology of the nanoparticles and they appear to have a heterogeneous surface. The recorded micrographs display a mixed morphology of cubic and rectangular nanoparticles. The particle and sizes varied depending upon the clumping of nanoparticles. The surface of the particles did not remain smooth, which may be due to their interaction with extract biomolecules, however, these nanographs match those of synthesized Cu NPs [37-39]. However, keeping the SEM results in mind, the predicted size of the nanoparticles ranged from 50 to $100 \mathrm{~nm}$. 


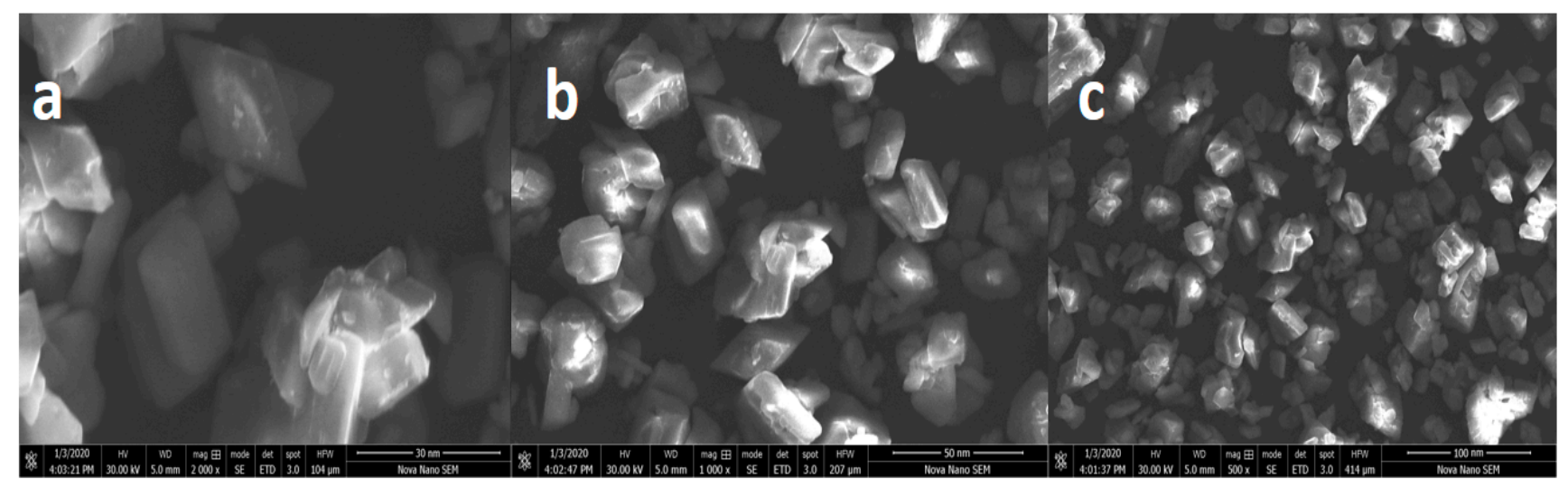

Figure 4. SEM micrographs of Fe-Cu BNPs at $30 \mathrm{~nm}(\mathbf{a}), 50 \mathrm{~nm}$ (b) and $100 \mathrm{~nm}$ (c).

\subsection{DPPH Radical-Scavenging Activity}

UV-visible spectra for various plant extract concentrations with Fe-Cu BNPs taken after adding the BNP solution, at different time intervals, clearly show the potential of $\mathrm{Fe}-\mathrm{Cu}$ BNPs, as presented in Figure 5. With the passage of time, absorbance of DPPH solution decreases and after $30 \mathrm{~min}$, the DPPH solution becomes colorless [40,41]. By increasing the concentration of BNPs, a sharp decrease in the absorbance of DPPH solution was observed.
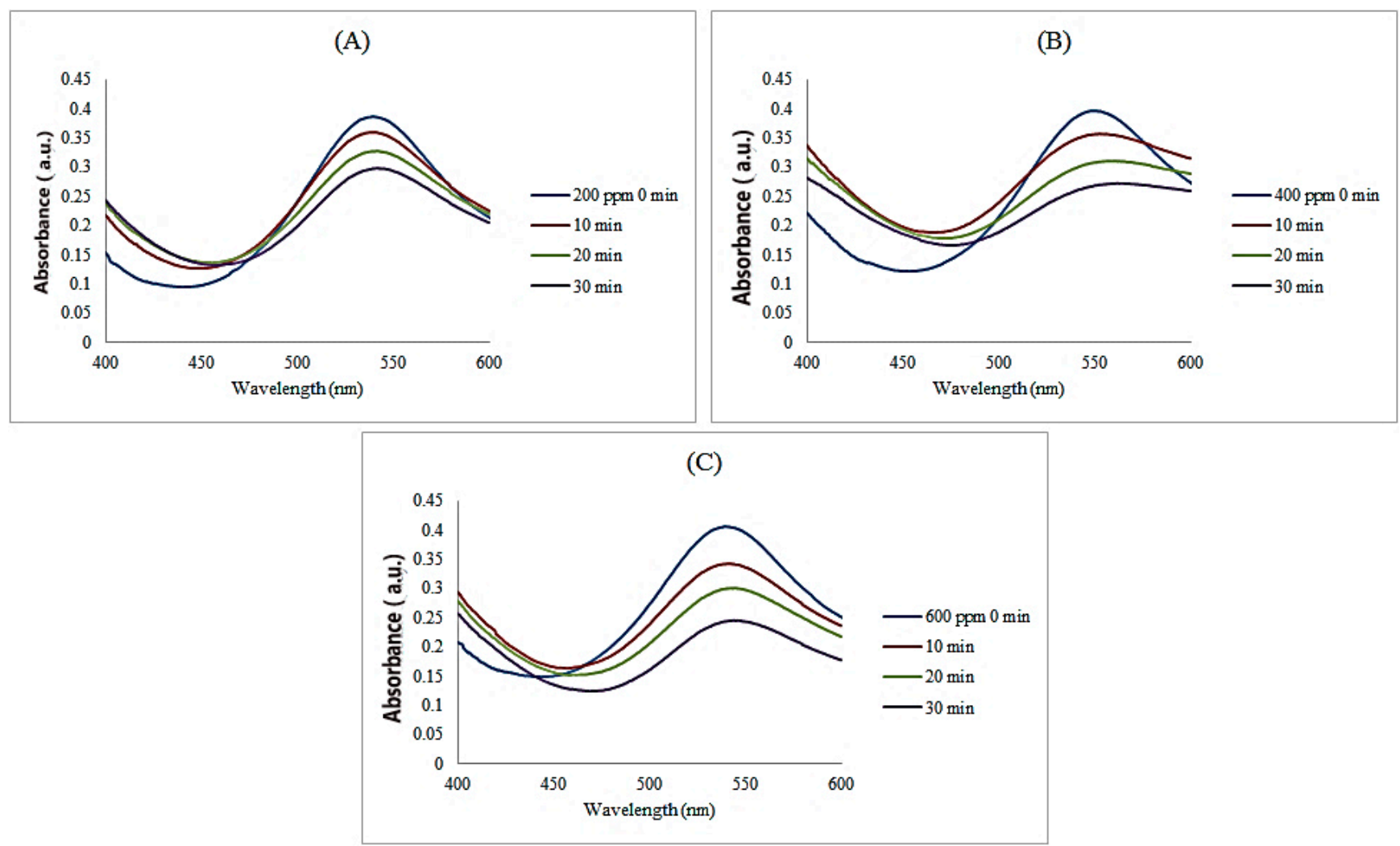

Figure 5. UV-visible spectra at different plant extract (Fe-Cu BNP) concentrations, i.e., 200 ppm (A), 400 ppm (B) and $600 \operatorname{ppm}(\mathrm{C})$.

\subsection{Kinetics of DPPH Radical-Scavenging Activity}

Kinetics of the radical scavenging activity of BNPs were examined using a UV/Vis spectrophotometer and an increase in the percentage of scavenging was witnessed. An efficient response has been observed in the kinetics of antioxidant potential by using various catalysts [42,43]. Spectra were recorded for reactions between DPPH solution and 
different concentrations of BNPs (200, 400 and $600 \mathrm{ppm}$ ) and then percentage of scavenging was plotted against time, as shown in Figure 6a. The graph in Figure 6b shows the effective antioxidant nature of DPPH where Fe-Cu BNPs behaved as acceptors. It is evident that at each concentration of BNPs, the percentage of scavenging increased with time as DPPH captured the radicals. Additionally, Figure $6 \mathrm{~b}$ shows that the relative inhibition of DPPH decreases by increasing plant extract concentration because the DPPH acts as a radical scavenger, i.e., antioxidant. Additionally, as the plant extract concentration increases, more $\mathrm{DPPH}$ is consumed.
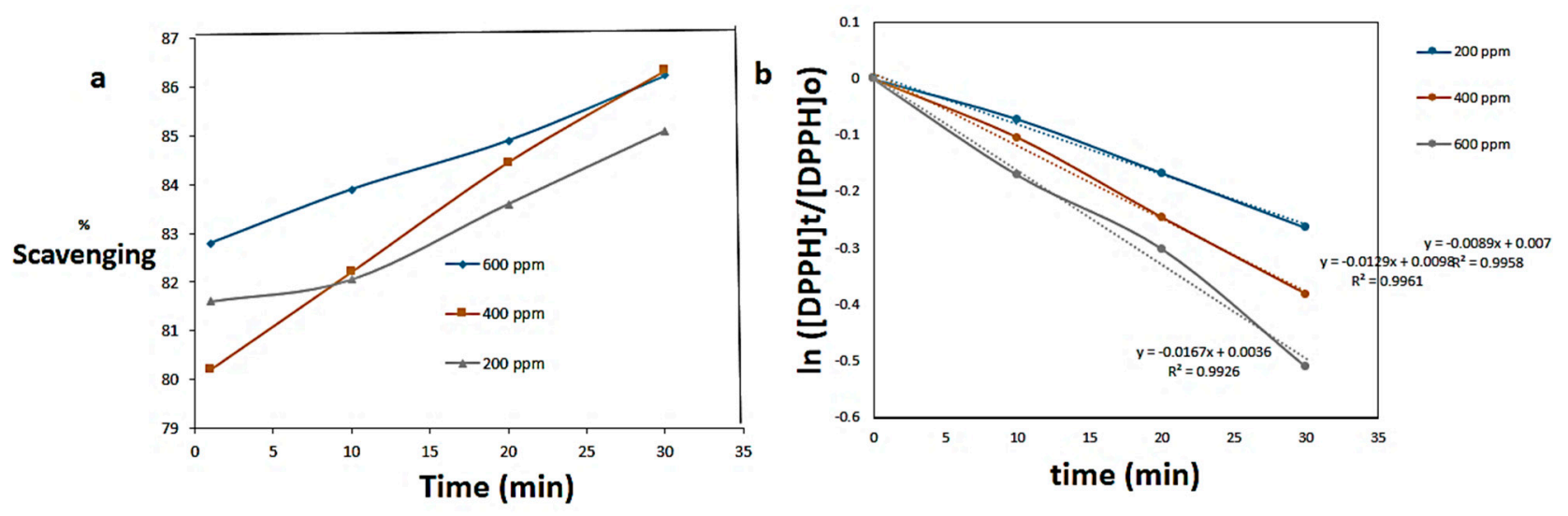

Figure 6. Comparative analysis of \% of scavenging by DPPH at different concentrations (Fe-Cu BNPs) of plant extract (a) and antioxidant activity of DPPH as a function of time (b).

The kinetics of DPPH as an antioxidant were examined following a pseudo-first order reaction using the concentration of [DPPH] using the following equation [44].

$$
-\mathrm{d}[\mathrm{DPPH}] / \mathrm{dt}=\mathrm{k}_{\mathrm{app}} \cdot[\mathrm{DPPH}]
$$

Kinetic parameters, including apparent rate constant " $k_{\text {app }}\left(\mathrm{s}^{-1}\right)^{\prime \prime}$ and half life " $\left(\mathrm{t}_{1 / 2}\right)$ $(\mathrm{s})^{\prime \prime}$, were determined, as shown in Table 1. It indicates that by increasing the concentration of BNPs, the rate constant increases, which refers to the increase in antioxidant activity.

Table 1. Different kinetic parameters at various concnetrations of DPPH.

\begin{tabular}{cccc}
\hline $\begin{array}{c}\text { Concentration } \\
(\mathbf{p p m})\end{array}$ & Slope & $\begin{array}{c}\text { Apparent Rate Constant } \\
\mathbf{k}_{\mathbf{a p p}} \mathbf{( \mathbf { s } ^ { - 1 } )}\end{array}$ & $\begin{array}{c}\text { Half Life } \\
\left(\mathbf{t}_{\mathbf{1} / \mathbf{2}}\right)\end{array}$ \\
\hline 200 & -0.0089 & 0.0089 & 77.86516 \\
400 & -0.0129 & 0.0129 & 53.72093 \\
600 & -0.0167 & 0.0167 & 41.49700 \\
\hline
\end{tabular}

\subsection{Catalytic Activity/Dye Degradation}

\subsubsection{In the Absence of Fe-Cu BNP Catalysts}

Different industries are continuously releasing organic dyes into water streams. Being toxic, carcinogenic and hazardous in nature, these dyes are the biggest threat to living things. The major source of methylene blue in water is the paper and cloth industry, which releases approximately $60 \mathrm{~g} / \mathrm{L}$ annually. The reduction of such pollutants from waste water is a current topic of research $[45,46]$. Researchers have reported catalytic degradation of dyes as one of the best tools for the removal of dyes from a water medium. In the current study, an attempt was made to remove dye from a water medium using a catalytic degradation process. In an initial experimental setup, degradation of MB dye was observed in the presence of $\mathrm{NaBH}_{4}$, as seen in Figure 7a. It is clear that there is no obvious decrease in the absorbance curves at $665 \mathrm{~nm} \lambda_{\max }$, showing that $\mathrm{NaBH}_{4}$ were unable to reduce the 
cationic dye, although the reaction took place at the surface of the catalyst, which carried out electron transfer from $\mathrm{BH}_{4}{ }^{-}$to $\mathrm{MB}$.
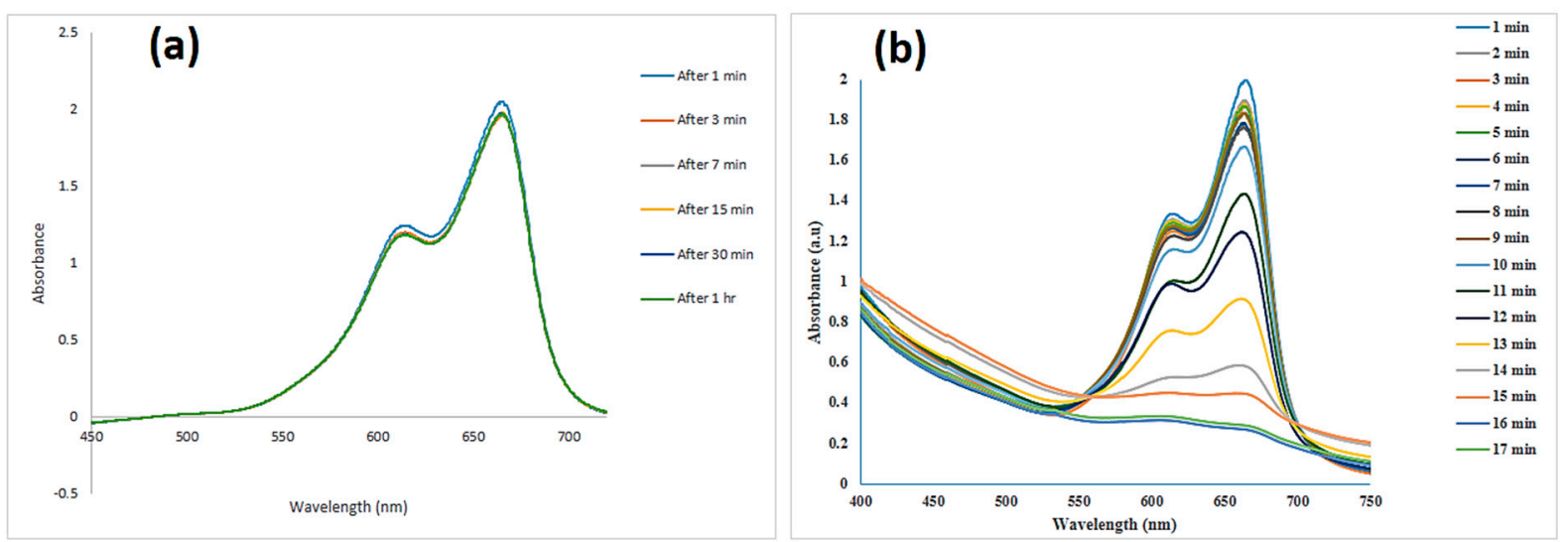

Figure 7. UV-visible spectra of reaction between $\mathrm{MB}$ and $\mathrm{NaBH}_{4}$ in the absence of $\mathrm{Fe}-\mathrm{Cu} \mathrm{BNPs}(\mathbf{a})$ and in the presence of 200 ppm of Fe-Cu BNPs (b).

\subsubsection{In the Presence of Fe-Cu BNP Catalysts}

Degradation of MB dye in the presence of Fe-Cu BNPs was also carried out to evaluate the catalytic potential of synthesized bimetallic nanoparticles. For this purpose, optimized conditions were recorded for this reaction, i.e., $26 \mathrm{mM} \mathrm{NaBH}_{4}, 0.5 \mathrm{~mL}$ of $100 \mathrm{ppm} \mathrm{Fe}-\mathrm{Cu}$ BNPs and $6.8 \mathrm{pH}$ at $22{ }^{\circ} \mathrm{C}$. The results in Figure $7 \mathrm{~b}$ reveal that the reduction was effective and occurred within just $17 \mathrm{~min}$, and reduction of $\mathrm{MB}$ was monitored every min. The reduction catalysis of MB occurred by the Langmuir-Hinshelwood (LH) mechanism that is generally followed by a reduction of organic pollutants $[47,48]$. According to the $\mathrm{LH}$ mechanism, the role of Fe-Cu BNPs in catalysis could be elucidated by electron transfer from a donor $\left(\mathrm{NaBH}_{4}\right)$ to an acceptor (dyes). Additionally, more active sites were available on the surface of the catalyst for the incoming substrate to adsorb, leading to the reduction reaction. The heterogeneous Fenton type reaction catalyzed by Fe-Cu BNPs occurs by surface reactions incorporating both $\mathrm{Fe}$ and $\mathrm{Cu}$ active sites [47].

The mechanism shows the $-\mathrm{N}=\mathrm{N}-$ (present in $\mathrm{MB}$ ) breakage due to an electron pair from $\mathrm{BH}_{4}{ }^{-}$on the surface of the Fe-Cu BNP, which acts as an $\mathrm{e}^{-}$transferee. Previously, Yan $\mathrm{Hu}$ and coworkers reported research on the reduction of MB dye by using Fe-Cu BNPs [48], but they did not focus on the catalytic reduction of MB.

\subsubsection{Kinetics of Catalytic Activity}

By using the degradation spectra monitored with a UV/Vis spectrophotometer, kinetic studies were also performed. The reaction between $\mathrm{MB}$ and $\mathrm{NaBH}_{4}$ on the surface of $\mathrm{Fe}-\mathrm{Cu}$ BNPs was pseudo-first order, in which $\mathrm{NaBH}_{4}$ was taken in large excess as compared to $\mathrm{MB}$ $\left(\left[\mathrm{NaBH}_{4}\right] \gg>>[\mathrm{MB}]\right)$. It was found that the catalysis followed the Langmuir-Hinshelwood mechanism in which $\mathrm{NaBH}_{4}$ and $\mathrm{MB}$ react in succession on the surface of the catalyst. The slope of the graph (ln $A_{t} / A_{o}$ vs. time $t$ ) in Figure 8 shows the apparent rate constant from which we can calculate the rate of reaction. This $k_{a p p}$ value determined from the graph is $0.2982 \mathrm{~min}^{-1}$ and shows the effectiveness of Fe-Cu BNPs. It is clear from the results that there is no decrease in the $\ln A_{t} / A_{o}$ value from 1 to $10 \mathrm{~min}$, which is due to the fact that at the start of the reaction, the substrate and reducing agent diffuse towards the surface of the Fe-Cu BNP catalyst and this time is known as the induction time. After $10 \mathrm{~min}$, a dip in the straight line gives the slope value, presented in the inset of Figure 8. This was the reaction time in which $\mathrm{NaBH}_{4}$ and MB interacted with each other on the Fe-Cu BNPs and the reaction started. This reaction finally ended at 15 and $16 \mathrm{~min}$ when a colorless solution was obtained, which meant no reactive species were left in the reaction container. 


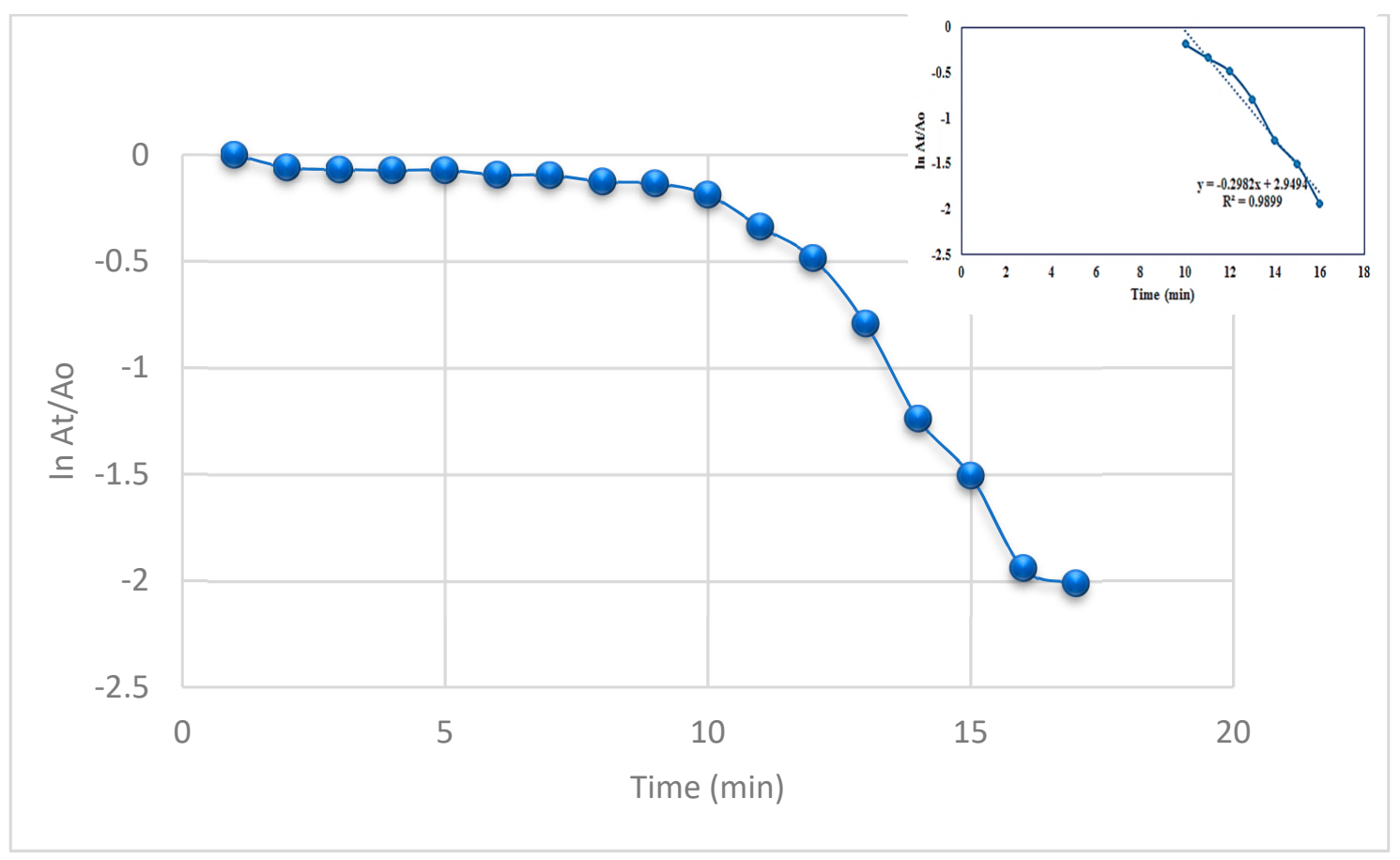

Figure 8. Dependence of absorbance ( $I n A_{t} / A_{o}$ ) on change in time $(t)$ in optimized conditions.

Ixora finlaysoniana extract, when isolated from the n-hexane mixture, displayed a chemical composition comprising a hydrocarbon alcohol, nonacosanol, amyrin, 3-hydroxyhexan5-olide, gallic acid, protocatechuic acid, $\beta$-sitostreol glucoside and sitosterol [48]. The most likely mechanism is based upon both hydrogen bond interactions and electrostatic interactions between the plant metabolites and bi-metals.

\section{Conclusions}

The purpose of this research work was to synthesize Fe-Cu bimetallic nanoparticles (BNPs) by a green method. Ixora finlaysoniana, an East Asian medicinal plant, was used as a source of biomolecules to synthesize BNPs. The confirmation for the synthesis of nanoparticles was carried out with a UV spectrophotometer. Their size range was checked by a size distribution analyzer which confirmed the presence of metal nanoparticles in the nanosized range. In addition, FTIR analysis, XRD and SEM studies confirmed the formation and structure of BNPs. The antioxidant potential in terms of radical-scavenging potential was determined by employing a DPPH assay and synthesized metal nanoparticles exhibited good antioxidant properties. The catalytic activity was determined using methylene blue dye as a substrate and sodium borohydride as a reducing agent. Results revealed that BNPs can effectively degrade the dye present in a water medium. Kinetic studies confirmed pseudo-first order reactions for both the radical-scavenging and catalytic activity. All the results of characterization and different studies proved that Fe-Cu BNPs can be successfully fabricated using Ixora finlaysoniana extract. Furthermore, these BNPs can be employed for radical scavenging and catalytic activities. Therefore, these Fe-Cu BNPs could attain much importance because they can meet the increasing demand for efficient and active nanoparticles in a sustainable, economical and ecofriendly way.

Author Contributions: U.Y. and S.I. designed the research scheme and performed the experimental part. S.T.H., F.A., F.H. and Z.S. analyzed the data and measurements. M.P., S.K. and S.B. wrote the manuscript. Validation, F.T.J., A.S., Z.A. and A.A.G. did the proofreading. M.O. and M.M.A.-A. performed the characterization analysis. Data Curation, S.A. All authors have read and agreed to the published version of the manuscript. 
Funding: The authors are grateful to the Deanship of Scientific Research, King Saud University for funding through Vice Deanship of Scientific Research Chairs and thankful to the financial support funded by the Deanship of Scientific Research at Princess Nourah bint Abdulrahman University through the Fast-track Research Funding Program.

Institutional Review Board Statement: Not applicable.

Informed Consent Statement: Not applicable.

Data Availability Statement: Data are contained within article.

Conflicts of Interest: The authors declare no conflict of interest.

\author{
Abbreviations \\ Iron-copper bimetallic nanoparticles (Fe-Cu BNPs), 1,1-diphenyl-2-picrylhydrazyl (DPPH), \\ scanning electron microscopy (SEM), X-ray diffraction (XRD), Fourier transform infrared spectroscopy \\ (FTIR) and methylene blue (MB).
}

\title{
References
}

1. Cheng, D.; Ngo, H.H.; Guo, W.; Chang, S.W.; Nguyen, D.D.; Liu, Y.; Wei, Q.; Wei, D. A critical review on antibiotics and hormones in swine wastewater: Water pollution problems and control approaches. J. Hazard. Mater. 2020, 387, 121682. [CrossRef]

2. Bibi, S.; Ahmad, A.; Anjum, M.A.R.; Haleem, A.; Siddiq, M.; Shah, S.S.; Al Kahtani, A. Photocatalytic degradation of malachite green and methylene blue over reduced graphene oxide ( $\mathrm{rGO}$ ) based metal oxides $\left(\mathrm{rGO}-\mathrm{Fe}_{3} \mathrm{O}_{4} / \mathrm{TiO}_{2}\right)$ nanocomposite under UV-visible light irradiation. J. Environ. Chem. Eng. 2021, 9, 105580. [CrossRef]

3. Mehdizadeh, P.; Orooji, Y.; Amiri, O.; Salavati-Niasari, M.; Moayedi, H. Green synthesis using cherry and orange juice and characterization of $\mathrm{TbFeO}_{3}$ ceramic nanostructures and their application as photocatalysts under UV light for removal of organic dyes in water. J. Clean. Prod. 2020, 252, 119765. [CrossRef]

4. Ahmad, I.; Jamal, M.A.; Iftikhar, M.; Ahmad, A.; Hussain, S.; Asghar, H.; Saeed, M.; Yousaf, A.B.; Karri, R.R.; Al-Kadhi, N.S.; et al. Lanthanum-zinc binary oxide nanocomposite with promising heterogeneous catalysis performance for the active conversion of 4-nitrophenol into 4-aminophenol. Coatings 2021, 11, 537. [CrossRef]

5. Khatri, J.; Nidheesh, P.V.; Singh, T.A.; Kumar, M.S. Advanced oxidation processes based on zero-valent aluminium for treating textile wastewater. Chem. Eng. J. 2018, 348, 67-73. [CrossRef]

6. Robinson, T.; McMullan, G.; Marchant, R.; Nigam, P. Remediation of dyes in textile effluent: A critical review on current treatment technologies with a proposed alternative. Bioresour. Technol. 2001, 77, 247-255. [CrossRef]

7. Padhi, B. Pollution due to synthetic dyes toxicity \& carcinogenicity studies and remediation. Int. J. Environ. Sci. 2012, 3, 940-955.

8. Khan, S.; Shah, S.S.; Anjum, M.A.R.; Khan, M.R.; Janjua, N.K. Electro-oxidation of ammonia over copper oxide impregnated $\gamma-\mathrm{Al}_{2} \mathrm{O}_{3}$ nanocatalysts. Coatings 2021, 11, 313. [CrossRef]

9. Nagajyothi, P.C.; Prabhakar Vattikuti, S.V.; Devarayapalli, K.C.; Yoo, K.; Shim, J.; Sreekanth, T.V.M. Green synthesis: Photocatalytic degradation of textile dyes using metal and metal oxide nanoparticles-latest trends and advancements. Crit. Rev. Environ. Sci. Technol. 2020, 50, 2617-2723. [CrossRef]

10. Ahmad, A.; Jini, D.; Aravind, M.; Parvathiraja, C.; Ali, R.; Kiyani, M.Z.; Alothman, A. A novel study on synthesis of egg shell based activated carbon for degradation of methylene blue via photocatalysis. Arab. J. Chem. 2020, 13, 8717-8722. [CrossRef]

11. Bassano, C.; Deiana, P.; Vilardi, G.; Verdone, N. Modeling and economic evaluation of carbon capture and storage technologies integrated into synthetic natural gas and power-to-gas plants. Appl. Energy 2020, 263, 114590. [CrossRef]

12. Vilardi, G.; Rodríguez-Rodríguez, J.; Ochando-Pulido, J.M.; Verdone, N.; Martinez-Ferez, A.; Di Palma, L. Large laboratory-plant application for the treatment of a Tannery wastewater by Fenton oxidation: Fe (II) and nZVI catalysts comparison and kinetic modelling. Process Saf. Environ. Prot. 2018, 117, 629-638. [CrossRef]

13. Astruc, D. Introduction: Nanoparticles in catalysis. Chem. Rev. 2020, 120, 461-463. [CrossRef] [PubMed]

14. Aravind, M.; Ahmad, A.; Ahmad, I.; Amalanathan, M.; Naseem, K.; Mary, S.M.M.; Parvathiraja, C.; Hussain, S.; Algarni, T.S.; Pervaiz, M.; et al. Critical green routing synthesis of silver NPs using jasmine flower extract for biological activities and photocatalytical degradation of methylene blue. J. Environ. Chem. Eng. 2020, 9, 104877. [CrossRef]

15. Sharma, G.; Kumar, A.; Sharma, S.; Naushad, M.; Dwivedi, R.P.; ALOthman, Z.A.; Mola, G.T. Novel development of nanoparticles to bimetallic nanoparticles and their composites: A review. J. King Saud Univ. Sci. 2019, 31, 257-269. [CrossRef]

16. Amen, T.W.; Eljamal, O.; Khalil, A.M.; Sugihara, Y.; Matsunaga, N. Methane yield enhancement by the addition of new novel of iron and copper-iron bimetallic nanoparticles. Chem. Eng. Process. Process Intensif. 2018, 130, 253-261. [CrossRef]

17. Viotti, P.; Tatti, F.; Rossi, A.; Luciano, A.; Marzeddu, S.; Mancini, G.; Boni, M.R. An eco-balanced and integrated approach for a more-sustainable msw management. Waste Biomass Valoriz. 2020, 11, 5139-5150. [CrossRef]

18. Nandhini, N.T.; Rajeshkumar, S.; Mythili, S. The possible mechanism of eco-friendly synthesized nanoparticles on hazardous dyes degradation. Biocatal. Agric. Biotechnol. 2019, 19, 101138. [CrossRef] 
19. Tang, J.; Wang, J. Iron-copper bimetallic metal-organic frameworks for efficient Fenton-like degradation of sulfamethoxazole under mild conditions. Chemosphere 2020, 241, 125002. [CrossRef]

20. Hu, C.Y.; Lo, S.L.; Liou, Y.H.; Hsu, Y.W.; Shih, K.; Lin, C.J. Hexavalent chromium removal from near natural water by copper-iron bimetallic particles. Water Res. 2010, 44, 3101-3108. [CrossRef]

21. Yasmeen, F.; Raja, N.I.; Razzaq, A.; Komatsu, S. Proteomic and physiological analyses of wheat seeds exposed to copper and iron nanoparticles. Biochim. et Biophys. Acta (BBA)-Proteins Proteom. 2017, 1865, 28-42. [CrossRef]

22. Duan, H.; Wang, D.; Li, Y. Green chemistry for nanoparticle synthesis. Chem. Soc. Rev. 2015, 44, 5778-5792. [CrossRef]

23. Hussain, I.; Singh, N.B.; Singh, A.; Singh, H.; Singh, S.C. Green synthesis of nanoparticles and its potential application. Biotechnol. Lett. 2016, 38, 545-560. [CrossRef]

24. Devi, T.B.; Ahmaruzzaman, M. Green synthesis of silver, copper and iron nanoparticles: Synthesis, characterization and their applications in wastewater treatment. In Green Metal Nanoparticles: Synthesis, Characterization and Their Applications; Kanchi, S., Ahmed, S., Eds.; Wiley-Scrivener: Austin, TX, USA, 2018.

25. Ghotekar, S. A review on plant extract mediated biogenic synthesis of CdO nanoparticles and their recent applications. Asian J. Green Chem. 2019, 3, 187-200.

26. Roopan, S.M.; Surendra, T.V.; Elango, G.; Kumar, S.H.S. Biosynthetic trends and future aspects of bimetallic nanoparticles and its medicinal applications. Appl. Microbiol. Biotechnol. 2014, 98, 5289-5300. [CrossRef] [PubMed]

27. Ali, A.I.; Tohamy Ibrahim, M.; Meselhy, K.; Temraz, A.; Sleem, A. Composition and bioactivities of the essential oil of Ixora finlaysoniana wall. ex G. Don.(family rubiaceae). J. Essent. Oil Bear. Plants 2015, 18, 754-766. [CrossRef]

28. Abdel-Aziz, H.M.; Farag, R.S.; Abdel-Gawad, S.A. Carbamazepine removal from aqueous solution by green synthesis zero-valent iron/Cu nanoparticles with Ficus Benjamina leaves' extract. Int. J. Environ. Res. 2019, 13, 843-852. [CrossRef]

29. Shawky, M. Phytochemical and biological investigation of Ixora finlaysoniana wall. Ex. G. Don. growing in egypt. Al-Azhar J. Pharm. Sci. 2016, 54, 86-102.

30. Iqbal, S.; Younas, U.; Chan, K.W.; Zia-Ul-Haq, M.; Ismail, M. Chemical composition of artemisia annua L. leaves and antioxidant potential of extracts as a function of extraction solvents. Molecules 2012, 17, 6020-6032. [CrossRef]

31. Nguyen, T.B.; Dong, C.D.; Huang, C.P.; Chen, C.W.; Hsieh, S.L.; Hsieh, S. Fe-Cu bimetallic catalyst for the degradation of hazardous organic chemicals exemplified by methylene blue in Fenton-like reaction. J. Environ. Chem. Eng. 2020, 8, 104139. [CrossRef]

32. Wang, Y.; Zhao, H.; Zhao, G. Iron-copper bimetallic nanoparticles embedded within ordered mesoporous carbon as effective and stable heterogeneous Fenton catalyst for the degradation of organic contaminants. Appl. Catal. B Environ. 2015, 164, 396-406. [CrossRef]

33. Devi, H.S.; Boda, M.A.; Shah, M.A.; Parveen, S.; Wani, A.H. Green synthesis of iron oxide nanoparticles using Platanus orientalis leaf extract for antifungal activity. Green Process. Synth. 2019, 8, 38-45. [CrossRef]

34. Ramyadevi, J.; Jeyasubramanian, K.; Marikani, A.; Rajakumar, G.; Rahuman, A.A.; Santhoshkumar, T.; Kirthi, A.V.; Jayaseelan, C.; Marimuthu, S. Copper nanoparticles synthesized by polyol process used to control hematophagous parasites. Parasitol. Res. 2011, 109, 1403-1415. [CrossRef]

35. Chandra, S.; Kumar, A.; Tomar, P.K. Synthesis and characterization of copper nanoparticles by reducing agent. J. Saudi Chem. Soc. 2014, 18, 149-153. [CrossRef]

36. Zeleňáková, A.; Hrubovčák, P.; Kapusta, O.; Kučerka, N.; Kuklin, A.; Ivankov, O.; Zeleňák, V. Size and distribution of the iron oxide nanoparticles in SBA-15 nanoporous silica via SANS study. Sci. Rep. 2019, 9, 1-9. [CrossRef] [PubMed]

37. Asghar, M.A.; Zahir, E.; Asghar, M.A.; Iqbal, J.; Rehman, A.A. Facile, one-pot biosynthesis and characterization of iron, copper and silver nanoparticles using Syzygium cumini leaf extract: As an effective antimicrobial and aflatoxin B1 adsorption agents. PLoS ONE 2020, 15, e0234964. [CrossRef] [PubMed]

38. Hassanien, R.; Husein, D.Z.; Al-Hakkani, M.F. Biosynthesis of copper nanoparticles using aqueous Tilia extract: Antimicrobial and anticancer activities. Heliyon 2018, 4, e01077. [CrossRef] [PubMed]

39. Bhuiyan, M.S.H.; Miah, M.Y.; Paul, S.C.; Aka, T.D.; Saha, O.; Rahaman, M.M.; Sharif, M.J.I.; Habiba, O.; Ashaduzzaman, M. Green synthesis of iron oxide nanoparticle using Carica papaya leaf extract: Application for photocatalytic degradation of remazol yellow RR dye and antibacterial activity. Heliyon 2020, 6, e04603. [CrossRef]

40. Lien, H.-L.; Jhuo, Y.-S.; Chen, L.-H. Effect of heavy metals on dechlorination of carbon tetrachloride by iron nanoparticles. Environ. Eng. Sci. 2007, 24, 21-30. [CrossRef]

41. Herlekar, M.; Barve, S.; Kumar, R. Plant-mediated green synthesis of iron nanoparticles. J. Nanopart. 2014, 2014, 40614. [CrossRef]

42. Prasad, K.S.; Patra, A.; Shruthi, G.; Chandan, S. Aqueous extract of Saraca indica leaves in the synthesis of copper oxide nanoparticles: Finding a way towards going green. J. Nanotechnol. 2017, 2017, 7502610. [CrossRef]

43. Mou, Y.; Peng, Y.; Zhang, Y.; Cheng, H.; Chen, M. Cu-Cu bonding enhancement at low temperature by using carboxylic acid surface-modified Cu nanoparticles. Mater. Lett. 2018, 227, 179-183. [CrossRef]

44. Das, D.; Nath, B.C.; Phukon, P.; Dolui, S.K. Synthesis and evaluation of antioxidant and antibacterial behavior of CuO nanoparticles. Colloids Surf. B Biointerfaces 2013, 101, 430-433. [CrossRef]

45. Harshiny, M.; Iswarya, C.N.; Matheswaran, M. Biogenic synthesis of iron nanoparticles using Amaranthus dubius leaf extract as a reducing agent. Powder Technol. 2015, 286, 744-749. [CrossRef] 
46. Momen, H.M.; Haghi, B.; Morsali, A.; Ardalan, P.; Ardalan, T. Kinetic study of DPPH scavenging in the presence of mixture of Zinc and Vitamin C as an antioxidant. J. Chem. Health Risks 2012, 2, 2.

47. Arora, B.; Sethi, S.; Joshi, A.; Sagar, V.R.; Sharma, R.R. Antioxidant degradation kinetics in apples. J. Food Sci. Technol. 2018, 55, 1306-1313. [CrossRef]

48. Hashemi, S.M.B.; Brewer, M.S.; Safari, J.; Nowroozi, M.; Abadi Sherahi, M.H.; Sadeghi, B.; Ghafoori, M. Antioxidant activity, reaction mechanisms, and kinetics of Matricaria recutita extract in commercial blended oil oxidation. Int. J. Food Prop. 2016, 19, 257-271. [CrossRef] 